\title{
Chapter 17 \\ Drought Preparedness Policies and Climate Change Adaptation and Resilience Measures in Brazil: An Institutional Change Assessment
}

\author{
Emilia Bretan and Nathan L. Engle
}

\begin{abstract}
Brazil has historically coped with drought, a phenomenon that especially impacts the semi-arid lands of the Northeast. To deal with the various impacts of a current multi-year drought (2010-ongoing), the Government of Brazil, led by the Ministry of National Integration, partnered with the World Bank (WB) on a technical assistance program to foster proactive drought policy and management. The program works across sectors (climate/meteorology, water and sanitation, agriculture, environment, and disaster risk management) and levels (local, riverbasin, urban, state, regional and federal) in relation to the outcomes and stakeholders it aims to engage and influence, and trough the integration of WB Global Practices and programs.

Inspired by successful models and lessons from other countries, the program aims to contribute to greater climate change resilience and reach a broad community of beneficiaries. To achieve these objectives, partners convened to (1) build a Northeast Drought Monitor; and (2) pilot drought preparedness plans across Northeast.

This chapter showcases the program and highlights key-milestones and direct and indirect outcomes identified by 2015 . The institutional change process was assessed using qualitative analytical tools that integrate Outcome Mapping, the Capacity Development Results Framework, and Outcome Harvesting. Strengths, challenges, and outcomes (institutional changes) were identified, by tracking the program's contribution throughout its duration and at its completion.

The evidence shows that the initiative was able to convene key-regional and federal level multi-sector stakeholders at a decisive moment, resulting in an unprecedented bottom-up and regionally-led collaboration. Through the
\end{abstract}

E. Bretan $(\triangle)$

World Bank, Sāo Paulo, Brazil

e-mail: emiliabretan@gmail.com

N.L. Engle

Climate Policy Team, World Bank, Washington, DC, USA

e-mail: nengle@worldbank.org 
engagement and commitment of the partners, the program fostered and coordinated continuous sharing of knowledge, data, and work between service providers, secretariats, municipalities and other stakeholders from distinct sectors and scales of decision making. Thus, it influenced progress towards overcoming some of the historical challenges related to drought management in Brazil.

Keywords Drought $\bullet$ Climate change $\bullet$ Outcome harvesting $\bullet$ Resilience

\subsection{Introduction}

Extreme droughts and climate change are increasingly seen as important challenges to achieving green growth, improving agricultural livestock production, meeting water supply needs, and for residential users and commercial/industrial producers in Brazil (World Bank 2012). According to the World Bank's recent Turn Down the Heat reports, scientists expect drought phenomena to increase in frequency, duration, and intensity, ultimately translating to higher levels of evapotranspiration, reductions in arable land, and greater food insecurity in many countries and regions (World Bank 2012).

Traditional forms of dealing with drought, based on crisis management as opposed to proactive risk management (or drought preparedness) will likely not be able to tackle the devastating and long-lasting consequences expected from future climate change scenarios. In drought prone areas, such as the Brazilian semi-arid, drought preparedness appears as key to face these anticipated challenges.

Aligned with international discussions and successful initiatives from other countries, the Brazil Drought Preparedness and Climate Resilience non-lending technical assistance program (Drought NLTA), requested by the Government of Brazil (GoB), was initiated by The World Bank (WB) in July 2013 to support a process to shift the paradigm from reactive to proactive drought management.

The program aims to tackle historical challenges to the improvement of drought management in the country, through the promotion of knowledge exchange and through support for the development of drought preparedness measures and tools. Fostering drought resilience, and, as a consequence, climate change resilience, in the Brazilian case, also means promoting a strong effort of integration of institutions across sectors and levels, clarification and definition of roles, and the promotion of bottom-up and regionally-led initiatives, working towards a paradigm shift. The Drought NLTA was designed to support Brazilian partners towards these associated institutional and technical upgrades.

This chapter showcases the Drought NLTA program and highlights key-milestones and direct and indirect outcomes identified to date (the program is still being implemented at the time of drafting this chapter). It also presents the elected Planning, Monitoring and Evaluation (PM\&E) approach, one that parallels the complexity of the program, integrating the variety of the multi-sector partners' perspectives. Focusing on outcomes - understood as institutional changes - the PM\&E approach provides a framework to collect and analyze outcomes that looks 
beyond the control of the Drought NLTA and into the how the program influences its partners and stakeholders.

The evidence organized through the PM\&E approach shows that the Drought NLTA initiative was able to convene key-regional and federal level multi-sector stakeholders at a decisive moment, resulting in an unprecedented bottom-up and regionally-led collaboration. Through the engagement and commitment of the partners, the program linked and promoted coordinated and continuous sharing of knowledge, data, and work between service providers, secretariats, municipalities and other stakeholders from distinct sectors, states, and governmental levels. Thus, it influenced progress towards overcoming some of the historical challenges related to drought management in Brazil.

\subsection{Background}

Drought, or in Portuguese, "seca", is a not a new phenomenon to the Brazilian society, especially for those living in the Northeast semi-arid region of the country. The average annual rainfall in the area is roughly $800 \mathrm{~mm}$ per year and is characterized not only by the minimal rainfall, but also by the timing of the rainfall (i.e., the rain typically falls only during a concentrated portion of the year). Historically, severe droughts have occurred in the Brazilian semi-arid. The semiarid region, or the sertão is an area that reaches across nine Northeast states, covering an area of approximately $982,560 \mathrm{~km}^{2}$, and includes more than 1,000 municipalities and 22 million inhabitants.

To combat drought, Brazil, like many nations, has invested in solutions such as increased emergency lines of credit, renegotiation of agricultural debts, expansion of social support programs, (e.g., cash transfer programs to poor families and farmers in the case of crop losses or lack of water to support plantings), and water truck deliveries of emergency drinking water to rural communities. These measures have helped to mitigate the more dramatic effects of drought, that in the past included not only economic losses but also starvation, diseases, death, losses of crops and animals, migration, pillage, and migrations. To date, however, few initiatives have been focused on adopting a long-term approach to avoid drought related losses and to promote a more resilient society.

This traditional approach to managing droughts around the world is often referred to as the "hydro-illogical" cycle (Wilhite 2011), characterized by the adoption of emergency measures when the drought hits that are quickly abandoned as the drought fades (along with the fading of decision makers' memories of the need to be better prepared for the next one).

More severe droughts are expected to happen in the Brazilian semi-arid region with climate change and increasing demand for water resources (World Bank 2014a). The most recent one, began in 2010, and has been progressing and persisting through 2015. Considered the worst drought in decades, it is costing billions of Brazilian reais for emergency and structural actions and has led to 
considerable crop losses, thousands of cattle deaths. The drought has been threatening the considerable gains in terms of economic, social, and human development that the region has experienced in the past several decades and placing many communities at risk of slipping back into extreme poverty ${ }^{1}$ Reservoirs are at historically low levels, and in September, 2015, Ceará state had $80 \%$ of its municipalities depending on water trucks. ${ }^{2}$

Aligned with international discussions for improving drought resilience, most notably the High Level Meeting on National Drought Policy (HMNDP), in Geneva, Switzerland in March 2013, Brazil's Ministry of National Integration (MI) created an intra-ministerial work group to look critically at Brazil's drought management approaches, as well as to study the possibility of designing a national drought policy. ${ }^{3}$ At the HMNDP, Brazil declared its commitment to improve drought planning and management in order to reduce impacts and increase resilience to future droughts and climate change.

Within this context, the MI requested the World Bank to support a process to shift the paradigm from reactive to proactive drought management. Specifically, MI requested: (i) to help with an 'institutional upgrade' through structuring and facilitating a more permanent institutional approach and response to drought, and improving integration within and between federal and state institutions; and (ii) to help with a 'technical upgrade' through developing concrete drought monitoring tools and preparedness plans/protocols. The Brazil Drought Preparedness and Climate Resilience non-lending technical assistance program (Drought NLTA) was thus designed and initiated in July 2013 to address this request.

\subsection{The Drought NLTA Program Concept}

The nature of the main challenge that the Drought NLTA program aims to tackle (i.e., fostering proactive drought policy and management), necessitates in its design a cross-sector program both internally to the WB and externally with the various partners involved. Water, climate, agriculture, and disaster risk management are the four key-areas involved, and the activities also involve partners from related areas, such as environment.

Adding another layer to the complexity of the program, more than 120 professionals from 50 multi-sector partners are involved with the effort: representing the federal government, federal institutions that act both nationally and regionally,

\footnotetext{
${ }^{1}$ More information can be found here: http://www.brasil.gov.br/observatoriodaseca/index.html

${ }^{2}$ Source: "Seca: Ceará tem 146 municípios abastecidos por carros-pipa". Available at http://www. cearaagora.com.br/site/2015/09/seca-ceara-tem-146-municipios-abastecidos-por-carros-pipa/

${ }^{3}$ Source: Ministério da Integração Nacional (MI) e Instituto Interamericano de Cooperação para a Agricultura (IICA). 2013. Estudos Referentes ao Diagnóstico da Política nacional de Secas no Brasil: Relatório Contendo Diagnóstico e Embasamento para a Formulação de uma Política Nacional de Secas no Brasil. Consultor, Otamar de Carvalho.
} 
state and municipal level secretariats, technical agencies, universities and research centers, non-governmental organizations (including river basin committees), and the private sector.

Inspired by successful models and lessons from other countries ${ }^{4}$ the key components of the Drought NLTA include: (i) developing a Northeast Drought Monitor (DM); (ii) piloting drought preparedness plans (DPPs) for different sectors across the Northeast (urban water supply, rural rain-fed agriculture, and river basin management, each at different scales of planning); and (iii) the discussion and systematization of guidelines and principles towards a national drought policy (NDP). In the Results Framework, the first two components (i, DM and ii, DPP) compose the so-called "Northeast Regional Pilot Track" and the third piece (iii, NDP) is called the "National Track". A visual summary of this structure can be seen in the Fig. 17.1. The roles of key partners in the Drought NLTA are detailed in Table 17.1, referring to the different components of the Drought NLTA (i.e., i, ii, and/or iii).

The program design is based on the "three pillars of drought preparedness" framework: (a) monitoring and early warning; (b) vulnerability/resilience and

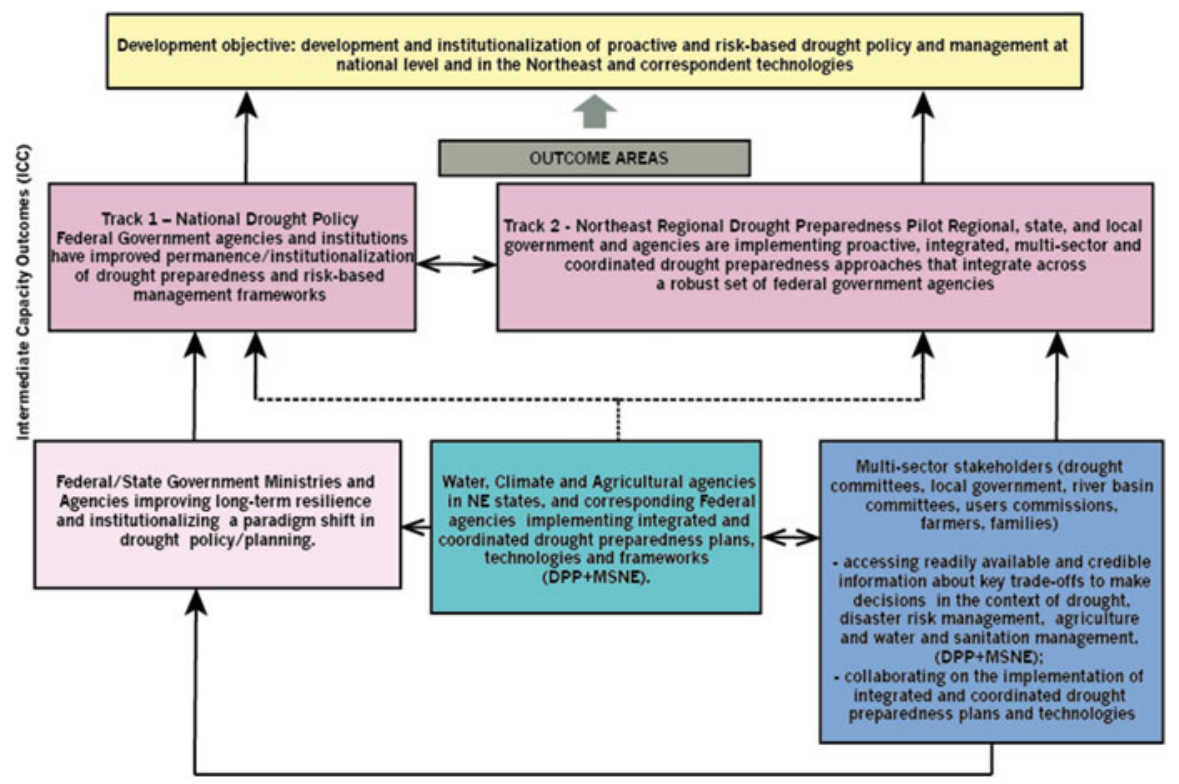

Fig. 17.1 Visual and summarized representation of the Drought NLTA results framework

\footnotetext{
${ }^{4}$ International institutions and professionals that have been developing drought preparedness plans, drought monitor and related initiatives and studies were key-partners for the Drought NLTA: US Drought Monitor and the National Drought Mitigation Center - NDMC, CONAGUA, the Mexican national water agency, academics from Spain, among others.
} 
Table 17.1 Summary of key-stakeholders involved in the development of the program and their responsibilities

\begin{tabular}{|c|c|c|}
\hline Area & Partner & $\begin{array}{l}\text { Roles/responsibilities in the drought } \\
\text { NLTA }\end{array}$ \\
\hline Development & Ministry of National Integration & $\begin{array}{l}\text { Supports the development of the DM } \\
\text { (i); organized a series of consultations } \\
\text { in the Northeast to discuss a NDP and } \\
\text { tools (iii) }\end{array}$ \\
\hline Water & National Water Agency & $\begin{array}{l}\text { Central Institution/Executive Secre- } \\
\text { tary of the DM (i); (i) Involved in the } \\
\text { design and implementation of DPPs } \\
\text { for River-Basins (ii) }\end{array}$ \\
\hline $\begin{array}{l}\text { Water and } \\
\text { climate }\end{array}$ & $\begin{array}{l}\text { Funceme (Ceará State Meteorological } \\
\text { and Water Resources Foundation) }\end{array}$ & $\begin{array}{l}\text { Regional leader of DM design and } \\
\text { implementation. (i); support to the } \\
\text { drought preparedness plans (ii) }\end{array}$ \\
\hline $\begin{array}{l}\text { Water and } \\
\text { environment }\end{array}$ & $\begin{array}{l}\text { INEMA - Bahia State Water } \\
\text { Resources and Environment Institute }\end{array}$ & $\begin{array}{l}\text { DM key-partner (part of the leading } \\
\text { group) (i) }\end{array}$ \\
\hline Water & $\begin{array}{l}\text { COGERH - Ceará Water Resources } \\
\text { Management Company }\end{array}$ & $\begin{array}{l}\text { Member of the DM design and } \\
\text { implementation team; (i) }\end{array}$ \\
\hline Water & $\begin{array}{l}\text { CAGECE - Ceará Water and Sanita- } \\
\text { tion Company }\end{array}$ & $\begin{array}{l}\text { Involved in the design and imple- } \\
\text { mentation of DPPs for Urban Water } \\
\text { and Sanitation (ii) }\end{array}$ \\
\hline Climate & $\begin{array}{l}\text { APAC - Pernambuco State Water and } \\
\text { Climate Agency }\end{array}$ & $\begin{array}{l}\text { DM key-partner (member of the lead- } \\
\text { ing group)(i); Supported the design } \\
\text { and implementation of DPP with } \\
\text { COMPESA (ii) }\end{array}$ \\
\hline $\begin{array}{l}\text { Water and } \\
\text { sanitation }\end{array}$ & $\begin{array}{l}\text { COMPESA - Pernambuco Sanitation } \\
\text { Company }\end{array}$ & $\begin{array}{l}\text { Involved in the design and imple- } \\
\text { mentation of DPPs for Urban Water } \\
\text { and Sanitation (ii) }\end{array}$ \\
\hline Agriculture & $\begin{array}{l}\text { EMPARN Rio Grande do Norte Agri- } \\
\text { cultural Research Company }\end{array}$ & $\begin{array}{l}\text { Members of the DM design and } \\
\text { implementation team (i); Involved in } \\
\text { the design and implementation of } \\
\text { DPPs for River-Basin (ii) }\end{array}$ \\
\hline Water & $\begin{array}{l}\text { Piranhas-Açu River Basin Committee- } \\
\text { Paraíba and Rio Grande do Norte states }\end{array}$ & $\begin{array}{l}\text { Members of the DM design and } \\
\text { implementation team (i); Involved in } \\
\text { the design and implementation of } \\
\text { DPPs for River-Basin (ii) }\end{array}$ \\
\hline Various & $\begin{array}{l}\text { Various multi-sector universities } \\
\text { water, climate and agriculture institu- } \\
\text { tions of the } 9 \text { Northeast states }\end{array}$ & $\begin{array}{l}\text { Support the design and implementa- } \\
\text { tion of the DM. (ii); Involved in dis- } \\
\text { cussions of the NDP process (iii) }\end{array}$ \\
\hline Various & $\begin{array}{l}\text { State and municipal level water and } \\
\text { agriculture secretariats (Piquet } \\
\text { Carneiro Municipality -CE) }\end{array}$ & $\begin{array}{l}\text { Involved in the design and imple- } \\
\text { mentation of DPPs for rural rain-fed } \\
\text { agriculture (ii) }\end{array}$ \\
\hline Agriculture & EMBRAPA - Brazilian & Data provider for the DM (i) \\
\hline Climate & INMET & Data provider for the DM (i) \\
\hline
\end{tabular}


Three Pillars of Drought Preparedness

1. Monitoring and forecasting/early warning

Foundation of a drought plan Indices/ indicators linked to impacts and action triggers

Feeds into the development/ delivery of information and decision-support tools
2. Vulnerability/resilience and impact assessment

Identifies who and what is at risk and why

Involves monitoring/ archiving of impacts to improve drought characterization
3. Mitigation and response planning and measures

Pre-drought programs and actions to reduce risks (short and long-term)

Well-defined and negotiated operational response plan for when a drought hits

Safety net and social programs, research and extension

Fig. 17.2 The 'three pillars of drought preparedness' that serve as the guiding framework for the Drought NLTA

impact assessment; and (c) mitigation and response planning and management. Fully and properly implemented, the pillars intend to contribute to better drought preparedness and build greater climate change resilience, with potential impacts in a diversity of sectors (e.g., water and sanitation, agriculture, environment, and disaster risk management), and reach a broad community of beneficiaries. Figure 17.2 provides an overview of the three pillars framework.

Elements of all the three pillars of drought preparedness are present in both the Drought NLTA tracks (the Northeast Regional Pilot Track and the National Track). The pillar that advanced more with the implementation of this Drought NLTA program was the first one, the monitoring and early warning pillar (essentially represented by the DM), followed by the third one, the mitigation and response planning and measures pillar (represented mainly by the DPPs).

The Drought NLTA implementation activities include trainings, workshops, field visits, study tours, and various meetings in and outside Brazil, with participation and guidance from numerous Brazilian national experts, and international partners, such as the National Drought Mitigation Center/US Drought Monitor (that collaborates closely with the initiative) -, the Government of Mexico (particularly Conágua - the National Water Commission) and several academic and local water utility partners from Spain, amongst others.

In these exchanges, stakeholders gather to learn, share their knowledge, communicate developments, set up priorities and agree upon responsibilities and institutional arrangements the program's phases and initiatives.

The WB team provides guidance, technical assistance, mobilization, communication, and convening services to help frame the conversation and keep the momentum of the paradigm shift, especially during potentially distracting moments, such as the October 2014 presidential and state government elections and the 2014 World Cup. 


\subsection{The PM\&E Approach}

\subsubsection{Description of the Approach}

As per the above description, the Drought NLTA exhibits characteristics of complex development intervention initiatives with a capacity development focus, such as:

- Multi-stakeholder context;

- Different perspectives from different actors on complex reform problems and solutions (lack of consensus about priorities);

- Distribution of the capacities to tackle the problems across actors, while no one actor is in full control (fragmented development context that makes it difficult to plan development efforts effectively with the broad ownership of stakeholders);

- Uncertainty about how to address the problems (a need for learning to adapt solutions);

- Deep-rooted institutional problems (that can impede results).

Considering the characteristics above, the WB has very limited or no control beyond the program's activities and outputs, whose outcomes are highly dependent upon the 'buy-in', initiative, and engagement of the partners involved. The design and implementation of an NDP could be supported by the WB through technical processes and capacity building, assessments from international experts, and with policy conceptualizing, and yet there is still no guarantee that by the end of the program such a policy will be in place.

The Drought NLTA then, calls for a non-traditional/non-linear (non-causeeffect) approach to PM\&E. To plan, monitor, and evaluate other initiatives that have faced similar challenges within the WB Group, the World Bank Institute (WBI), ${ }^{5}$ at the time of initiating the Drought NLTA, had been piloting tools that integrated the WB's Capacity Development Results Framework (CDRF) with Outcome Mapping (OM) and Outcome Harvesting (OH).

These three approaches were developed separately and are applied in a range of initiatives around the world, usually independently from one another. OM (Earl et al. 2001) was developed by the International Development Research Centre (IDRC), a Canadian development international non-governmental organization, to plan, monitor and evaluate some of its programs in developing countries that needed a strong participatory framework that could also engage partners in active change. OH (Wilson-Grau and Britt 2012) was developed by evaluators, strongly inspired by OM and Michael Patton's Utilization Focused Evaluation, to evaluate complex initiatives. The CDRF (Otoo et al. 2009) was developed by the WB to

\footnotetext{
${ }^{5}$ The World Bank Institute (WBI) is a global connector of knowledge, learning and innovation for poverty reduction. The WBI supports the World Bank's operational work and its country clients in this rapidly changing landscape by forging new dynamic approaches to capacity development through three areas of support: Open Knowledge, Collaborative Governance and Innovative Solutions. More information can be found at http://wbi.worldbank.org/wbi/
} 
plan, monitor, and evaluate its capacity development initiatives. The WBI pilot brought together key-concepts from these three approaches to develop specific tools to plan, monitor, and evaluate WB's initiatives that are multi-sector, with a capacity development focus, and that operate in complex environments. ${ }^{6}$

This piloted approach, which operationalizes a process and framework for systematically understanding outcomes that are structured around policy, institutional, and/or behavior change, has been synthesized into a guide (World Bank 2014b) and a book (World Bank 2014c), the latter sharing experiences of implementation of the tools in a range of initiatives supported by the WBI. Another document, "Designing a Multi--Stakeholder Results Framework: A toolkit to guide participatory diagnostics and planning for stronger results and effectiveness" (WBI 2013b), and other draft documents provided by the WBI (Gold 2013, 2014; WBI 2013a, 2014), guided the design of a Results Framework (RF) for the Drought NLTA.

The first step is the design of a multi-stakeholder RF. The step-by-step process involves the identification and analysis of challenges and constraints to institutional change, followed by the development of a change process that includes a development goal, institutional change outcomes, and intermediate capacity outcomes.

Some of the questions that guide the design of the change process (and that are seen again when harvesting outcomes to monitor and evaluate the initiative) are "Who needs to drive the needed changes; what local leaders, groups and citizens?; and How and When is change expected to happen?" (WBI 2013b)

The analytical framework - that can be adapted - incorporates the lenses of institutional and policy changes. Challenges and constraints are categorized, e.g., as "weak organizational capacity", or "inefficient policy instruments", while intermediate capacity outcomes (progress markers) that are part of the change process would fall into categories such as "raised awareness, enhanced knowledge or skills, improved consensus and teamwork, strengthened coalitions" and so on (WBI 2013b). These categories and tools guide the design of the multi-stakeholder RF.

The change process is focused on behavior/policy/institutional changes driven by the partners. To capture this, partners are aggregated into groups involved in similar activities and promoting similar changes. The change process envisioned for each group of partners is grouped under a so-called "Outcome Area".

The change process, therefore, strongly based on the OM concepts, "unpacks" full theory of change to learn how milestones link to more transformative changes, creating a scale of change to measure progress along the process. Outcomes are understood as what each social actor (or change agent) did, or is doing, that reflects a demonstrated change in awareness, knowledge or skills, collaborative action, or

\footnotetext{
${ }^{6}$ More information about these approaches can be found at http://www.outcomemapping.ca and http://betterevaluation.org/plan/approach/outcome_mapping (Outcome Mapping) and http:// betterevaluation.org/plan/approach/outcome_harvesting (Outcome Harvesting); Capacity Development Results Framework can be found at http://documents.worldbank.org/curated/en/2015/10/ 25228268/capacity-development-results-framework-strategic-results-oriented-approach-learningcapacity-development and at http://betterevaluation.org/resources/capacity_dev/results_framework
} 
Table 17.2 Example of the progress markers for "National Track"

Change agent: water, climate and agricultural agencies in Northeast states, and corresponding Federal agencies

\begin{tabular}{l|l}
\hline $\begin{array}{l}\text { Love to see (intermediate } \\
\text { capacity outcomes) }\end{array}$ & $\begin{array}{l}\text { Implementing integrated and coordinated drought prepared- } \\
\text { ness plans, technologies and frameworks }\end{array}$ \\
\hline Like to see (milestones) & $\begin{array}{l}\text { Collaborating through established networks with defined } \\
\text { governance rules }\end{array}$ \\
\cline { 2 - 2 } & $\begin{array}{l}\text { Engaging in and promoting capacity development activities } \\
\text { with multi-sector stakeholders }\end{array}$ \\
\cline { 2 - 2 } Expect to see (early outcomes) & $\begin{array}{l}\text { Agreeing on a common agenda towards pilot drought pre- } \\
\text { paredness plans and technologies/frameworks; }\end{array}$ \\
\cline { 2 - 2 } & $\begin{array}{l}\text { Increasing knowledge, data sharing and cooperation } \\
\text { Having increased know-how to plan drought mitigation and } \\
\text { response actions }\end{array}$ \\
\hline
\end{tabular}

the use of knowledge or innovative solutions. Outcomes might also describe deeper institutional changes relating to policy, citizen engagement or government accountability and organizational arrangements.

Initial involvement, awareness raising and other immediate outcomes are described as something we would expect to see; deeper engagement as what we would like to see, and institutional and sustainable change as what we would love to see as the program progresses to the end and beyond its limits. Examples of the progress markers for "National Track", extracted from the RF, are demonstrated in Table 17.2.

An $\mathrm{OH}$ approach mainly informs the monitoring and evaluation (implementation phase), helping the gathering and analysis of information on changes influenced by the project to inform decisions and next steps. It also captures intended and unintended outcomes during implementation to inform corrections and next steps and helps to evaluate and articulate how complex projects advance toward impact. The analytical framework provided by the WBI approach helps to make sense of the outcomes, demanding each described milestone or progress-marker to be sustained by more than one source of information to be considered valid (see Fig. 17.3).

The $\mathrm{OH}$ process includes a rigorous check of the significance of the outcome for the development goals the initiative and the partners want to achieve ("why does the change matter?") and the identification of the contribution of the development organization and of the partners.

One of the key-elements of $\mathrm{OM}$ and $\mathrm{OH}$ methodologies that are the basis of the WBI approach, is the fact that both acknowledge contribution and influence, but not necessarily attribution. Policy and institutional change processes, the focus of initiatives such as the Drought NLTA, are very susceptible to the influence from many factors and actors, as well as the- political environment, to name a few. As mentioned before, the design and implementation of an NDP could be strongly 


\section{Outcome information used for real-time learning}

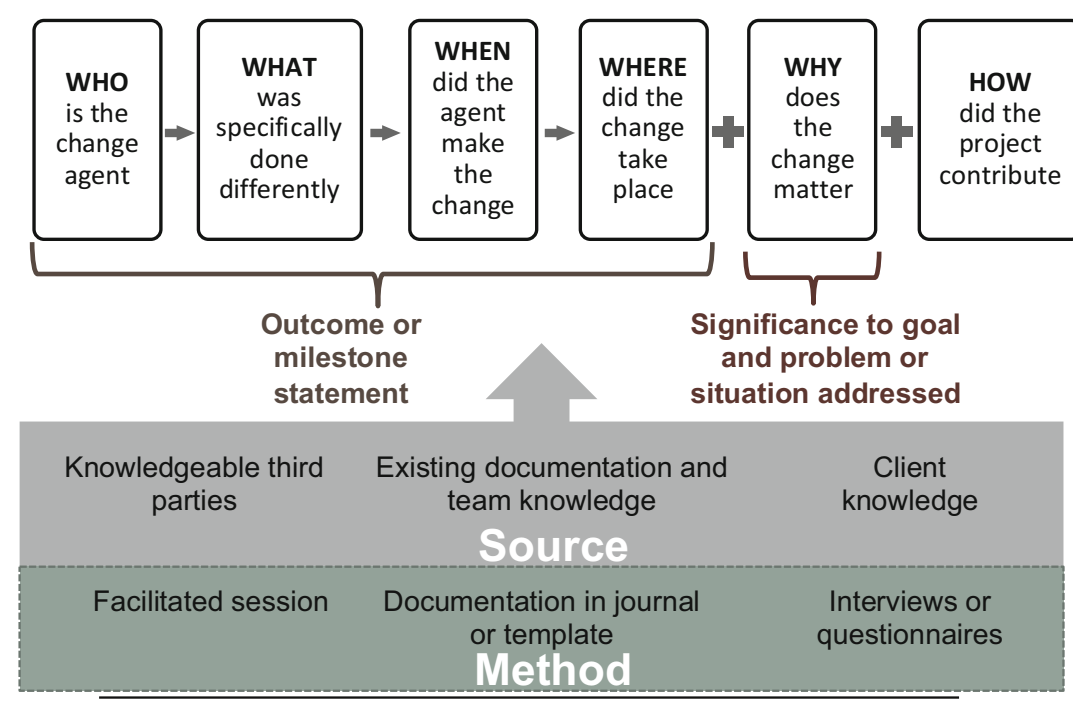

Fig. 17.3 Process for learning from outcome information, which is critical to the $\mathrm{OH}$ approach (Source World Bank 2014b, c)

supported by the WB's Drought NLTA, and yet there is still no guarantee that by the end of the program a national drought policy will be in place.

Sustainable changes (outcomes), therefore, are influenced by the Drought NLTA, but promoted and implemented by the stakeholders. A sustainable change (outcome) is understood as a result of complex collaboration processes that are naturally influenced (both positively and negatively) by many factors (commonly considered as "externalities" in other approaches).

The original design of the WBI pilot suggested the active engagement of the WB team and partners of the stakeholders in the design and implementation of the M\&E strategy, through meetings and workshops to promote joint reflection along lines of implementation, as well as the harvesting and analysis of outcomes. The specific conditions of the Drought NLTA, once implemented however, did not allow these opportunities. Nevertheless, with the intent to preserve the participatory nature that is one of the key-features of the approach, individual and group interviews, questionnaires, formal and informal interviews were carried out in person (taking advantage of regional workshops), through e-mail (written), and Skype or 
telephone, and were used to collect input at key points throughout the program as well to harvest outcomes and collect evidences of the change process. ${ }^{7}$

The implementation of the approach was developed after consultation with the key-stakeholders involved. Interviews and questionnaires captured the key-challenges and constraints to be tackled regarding drought management, as well as their vision and commitments to the change process.

Following the structure of the Drought NLTA described in its concept note, the change process for each group of partners was grouped under two key-areas (the National and Regional tracks, described above) and for each of these two broader areas, one ambitious long-term outcome was designed (Institutional Change Outcomes), describing the deepest possible transformations the Drought NLTA could influence, without losing sight of the reality of the context and what can be realistically achieved.

Although outputs (as well as inputs and activities) were described in the RF and monitored along the process, the key-focus of the approach has been the design, monitoring, and evaluation of outcomes.

To monitor the program, outcomes were 'harvested' through individual and group interviews, and examining of project documents and related materials to capture the (intended and unintended) relevant political and institutional changes generated throughout the process; allowing the WB team to understand its influence beyond the scope of the program and beyond its outputs. The harvesting of outcomes is not guided by the RF, but compared to it after the harvesting, allowing the identification and acknowledgment of unpredicted/unplanned direct and indirect outcomes (promoted by partners and by partners' partners). Similarly, designed indicators were monitored and provided support to the harvested outcomes. The findings were validated with the management team.

The final steps of the process are the selection of more relevant outcomes and substantiation. The substantiation requires that knowledgeable, independent third parties review the description and confirm the outcomes and the contributions of the program. In the Drought NLTA, the substantiation will be performed after the final harvesting of outcomes (fall/winter of 2015/2016). Substantiation represents an additional source of evidence that helps confirm the harvested outcomes reinforcing the triangulation process.

\footnotetext{
${ }^{7}$ The harvesting and analysis of outcomes can benefit significantly from opportunities to gather partners and the program team around the table to a shared reflection process, adding another layer of credibility to overcome the risk of reporting outcomes without evidence. It is possible to implement the approach by replacing this step of the process with a group or individual interviews, as it was adopted in the Drought NLTA, but the process may lose some of its richness by placing the collection and analysis in the hands of a single person.
} 


\subsection{Monitoring with Outcome Harvesting: Key-Findings and Outcomes ${ }^{8}$}

The findings are here presented around the two main Drought NLTA component tracks. Most of the time, the outcomes are strongly influencing each other and are contributing to both of the higher level goals designed for each of the program's tracks. The words in italic are the milestones designed in the RF for each group of partners. The numbers (1-11) at the end of each outcome description relate to the mapping of the outcomes (Fig. 17.4, item 17.5.3., below).

This approach does not pay particular attention to outputs and activities, considered as means to achieve the sustainable changes, or outcomes. Rather, the outputs and activities are mentioned as evidence that the WB or the partners have contributed to these outcomes.

\subsubsection{National Drought Policy Track: Key Findings}

- Advances in the dialogue towards a drought policy at the national level happened through the promotion, by the MI, of a series of regional seminars in the Northeast between April and May, 2014, to discuss policies for living/coping within the semi-arid region (1). These discussions included the endorsement of the DM and DPPs in the final recommendations of the discussion process, included in a document released in September, 1st, 2014, and delivered directly to MI. (5)

- A concrete measure to supporting and leveraging regionally-led drought preparedness initiatives and a step towards the institutionalization of a paradigm shift was a Technical Cooperation Agreement (MoU) signed in Brasília in

\footnotetext{
${ }^{8}$ Throughout the design and implementation of the PM\&E approach, more than 43 interviews (formal and informal) and questionnaires were applied with key-stakeholder representatives and Drought NLTA Team members between January 2014 and January 2015.

Other data collection methods used were review of documents and notes; observation of internal and external meetings and workshops; and on-line and press media information collected from March 2014 to January 2015, using Google Alert tool, and as sent to the Consultant by stakeholders and team members.

The sampling criteria adopted on the three phases of the M\&E work developed so far were purposeful sampling that could cover a wide range of institutions in different states of the Northeast, at the same time that it considered stakeholders involved in the program in different levels and in both National (drought policy) and Regional tracks.

While in the RF design and the mid-term monitoring report there was no specific concern about gender balance in the sampling, a more equal approach was adopted for the third cycle of interviews, when it was specifically requested that at least one woman should be represented in the groups of stakeholders to be interviewed (along with the other mentioned selection criteria).

Data were organized and analyzed through content analysis, identifying emerging patterns and triangulating to probe findings.
} 


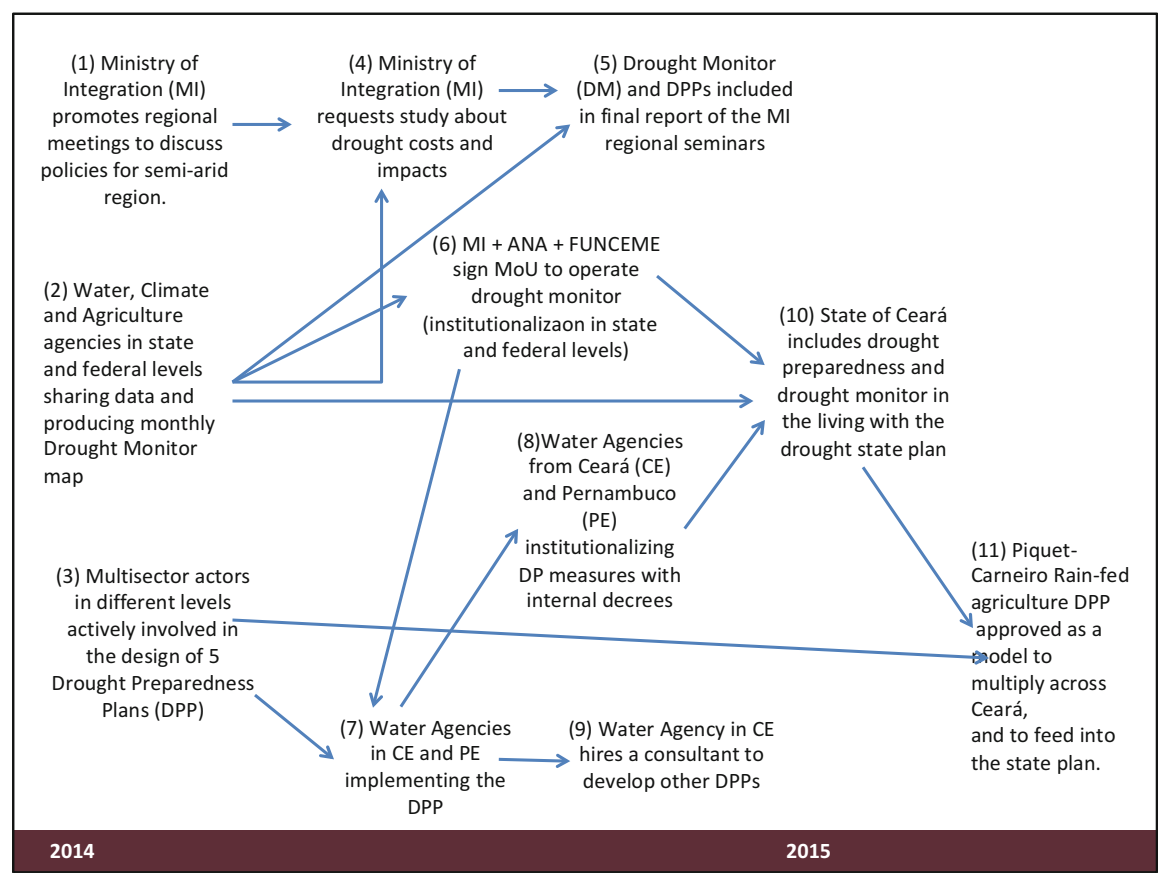

Fig. 17.4 Mapping of Drought NLTA key-outcomes harvested from May 2014 to January 2015

September, 2014, between federal and regional partners (i.e., specifically MI, ANA and FUNCEME), valid until December, 2015. (6) The MoU defines an institutional arrangement for the DM, an operational structure, and transition rules, with MI and ANA assuming key-roles in the governance (roles that are currently being supported by the strongest regional leader of this partnership, FUNCEME). The DM, as evidenced by the MoU, is also evidence of collaboration through established networks with defined governance rules, a milestone designed for the Northeast Regional Drought Preparedness track. The DM has been considered a concrete and tangible technological and institutional upgrade, and to some extent, it is buffered from strong political influence and politicization. The GoB considers the DM the foundation upon which any future NDP might be built.

- In mid-2014, halfway through the program, the MI requested additional assistance to the WB to evaluate the impacts and costs of the current drought across the Northeast to support improvements in vulnerability/resilience and impact assessment (progressing towards pillar 2 of the 3 drought preparedness pillars). This represents another concrete step towards institutionalization of a paradigm shift on drought management. (4) 


\subsubsection{Northeast Regional Drought Preparedness Pilot Track: Key-Findings}

- Increasing knowledge, data sharing and cooperation are evidenced by the experimental monthly DM maps that have been voluntarily and cooperatively produced by multi-sector professionals representing the nine northeast semi-arid states and many other stakeholders across the federal, regional, and local levels, since August, 2014. (2)

- Stakeholders involved in the development of each of the five DPPs have engaged in and promoted capacity development activities, such as the Drought NLTA regional workshops in January, May, and November, 2014. These workshops took place in Fortaleza (CE), Recife (PE) and Salvador (BA). (3)

- The participation and implementation of the DPPs has promoted increased know-how to plan drought mitigation and response actions. Water and sanitation companies from PE and CE have improved permanent and sustainable management capacity in what was declared to be a paradigm shift and a milestone in the history of the partners involved. (7) In November, 2014, and January, 2015, they reported the absence of a water-volume management culture prior to the DPP, with management criteria previously being defined ad hoc by the current manager and no specific operational protocols. They reported that internal decrees were on the way to institutionalizing drought preparedness measures. (8) The DPPs are, thus, have helped the culture of these institutions shift away from crisis to risk management. The water agencies that started the successful implementation of the DPP decided to hire a consultant to develop other DPPs to improve management of other reservoirs in Ceará. (9)

- In February 2015, the Government of Ceará State included drought preparedness measures and the DM in the "Living with Drought" State Plan and presented these measures in high level meetings led by the Governor of Ceará with the presence of the President of the Republic, Ministries, and several Governors of the Northeast. (10)

- The rain-fed agriculture DPP developed in Piquet-Carneiro, a small Municipality in Ceará, has been approved at the State level as a model to follow by other Municipalities across the state and the region, and to feed into the State Plan, as announced by the Governor of Ceará in Piquet-Carneiro on July 31st, 2015. (11)

\subsubsection{Mapping Key-Outcomes}

The WBI pilots developed a useful dissemination resource tool to highlight key-outcomes through organizing and displaying the outcomes in maps that can be presented in a timeline format, such as presented in the Fig. 17.4. ${ }^{9}$

\footnotetext{
${ }^{9}$ The outcomes can also be organized in a map that presents these and other theory of change elements, such as activities and inputs, as well as in other visual arrangements. Please see World Bank. 2014 c. Cases in Outcome Harvesting. Available at http://www.outcomemapping.ca/down load/en_Cases\%20in\%20Outcome\%20Harvesting.pdf, pages 15, 26.
} 
When looking at the map below, and reading the above findings, it is important to take into account that the process facilitated by the Drought NLTA is still recent. The activities started in mid-2013, and the first convening workshops to discuss the DM and the DPP started in January, 2014.

The process was fostered by the WB with strong voluntary adhesion of the partners. The relatively young nature of the program means that longer-term outcomes influenced directly or indirectly by the program are yet to crystalize, which explains that many of the milestones (outcomes) above reported are concentrated in the early and mid-term stages of the process.

The outcome map below (Fig. 17.4) shows the key-outcomes, collected along the years of 2014 and 2015 through review of documents and interviews conducted in November 2014 and January 2015 with the Drought NLTA team and partners. Outcomes will be again harvested and then substantiated (i.e., confirmed with key, knowledgeable informants) in early 2016.

\title{
17.6 Drought NLTA Implementation Lessons: Program Design and PM\&E Approach
}

\subsubsection{Drought NLTA Methodology Strengths and Challenges Assessment}

\begin{abstract}
Along with the harvesting of outcomes, a strengths and challenges assessment of the Drought NLTA methodology was conducted between November 2014 and January 2015, seeking to inform future similar collaborations around related topics (e.g., climate change resilience, drought preparedness or other complex issues regarding the influence of policy/institutional changes).

Individual or group interviews (up to three people), in person or via Skype, were conducted with key-partners involved in the DPPs and the DM. Essentially, they were asked to inform what had changed (in their practices, policies, behavior, knowledge, and institutions) since they started participating on the Drought NLTA activities and what were the key-strengths and challenges of the processes.

The results are summarized below.
\end{abstract}

\subsubsection{Challenges in the Drought NLTA Process}

Resistance was reported as challenge in the beginning of the program. The past efforts on drought management in Brazil have proven largely unsuccessful, so new initiatives are always looked upon with incredulity. Some respondents also mentioned that potential users of the DM have the perception that it is just another 
indicator or monitoring product. Although this resistance has faded with time, it persists among some stakeholders.

Institutional Fragilities were revealed along the process, ranging from the lack of personnel, high turnover or experience of partners' staffs, and the lack of planningbased management (which includes the lack of integration and knowledge of monitoring and other data).

The perception of these institutional fragilities as challenging is well documented in the notes of the third technical workshop (Salvador, INEMA (BA), November 19-20), and more specifically in the discussions about the monitoring network gaps and bottle necks that were identified through an institutional and IT analyses performed to support the DM process.

\subsubsection{Strengths in the Drought NLTA Process}

Commitment and Participation has been one of the keys to overcome the abovementioned resistance, resulting from a sum of factors:

- A regionally-led initiative (as opposed to one that is purely top-down);

- A technical-scientific process that is less susceptible to political interference;

- The immediate applicability of the concepts and studies to the ongoing drought in the region;

- The differentiation of the DM from other monitoring products, and;

- The highly participatory methodology that acknowledged the importance of the contributions from technicians as well as of the upper-level managers and policy makers.

Capacity Development and Institutional Strengthening resulted from the participation in the DPPs and the DM. Respondents agreed that there was an unequivocal gain in knowledge and improved capacity to deliver daily duties, with a broader and more complex vision than they had previously possessed before the initiation of the process, as the quote below illustrates:

"What can one say, what to argue, to a mayor, a governor? (. .) Now I can say we know the limitations of the dam. (...) Today I am sure I am adopting the correct measures. (...) "We feel secure to tell the press we are prepared (...)". - Manager of a water resources company in Pernambuco state, participant of a DPP. Interview and workshop notes

The institutional strengthening is directly linked with the capacity development. The interviewees reported that their institutions are stronger and more capable to deliver their services. This strengthening also derives from the methodologies used 
to develop the plan. The participation in the process and the implementation of the DPPs and DM helped in raising awareness, identifying the gaps and building a strong foundation for stronger institutions. It required partners to look for and organize information that, until then, had never been assembled and interpreted together.

The internalization of the new knowledge and the incorporation of new routines started immediately as the process commenced. These new routines and tools, information, and plans are intended to be used by the organizations beyond the scope of the DPPs/DM.

The contradiction between institutional fragility (pointed to by interviewees as a challenge, as seen above) and the institutional strengthening as a benefit (as indicated by the outcomes) is in fact, two sides of the same coin. Institutional fragility has been identified as a general constraint to development in Brazil, particularly in the same regions of the country as this program (i.e., the Northeast). In the case of the DM, while the key-partners of the process, FUNCEME, INEMA, APAC, ANA, MI, and INMET are more developed and capable of acquiring knowledge from international processes, training professionals in their institutions, adapting the technology and processes to the Brazilian reality, and even advancing it much more than expected and planned, many partners in the Northeast remain in much earlier stages of development. For example, some did not have permanent personnel or appropriate equipment. Institutional fragilities are, therefore, a challenge in the process of developing a shared and voluntary permanent cooperation process that needs periodic and reliable feeding of data.

Thus, the institutional strengthening appears as an absolutely critical benefit of the Drought NLTA process. Stakeholders report, in these early stages, awareness about their institutional fragilities and also a gradual shift in their perspectives, followed by changes in their practices and the institution with respect to new rules and procedures. The Drought NLTA process has also provided these professionals with concrete evidence for justifying requests to their superiors for technical and informational improvements to support the improved management of drought.

Integration of Sectors States and Institutions Institutions that did not initially have much dialogue with one another were brought together, or have further tightened already existing institutional relationships through the participation in the Drought NLTA process. This integration is happening across-sectors (meteorological, agricultural and water sectors), within sectors, and between institutions (hydro-meteorological institutes, water and sanitation companies, etc.), across states, and finally, across state and federal institutions.

The integrated vision of the drought and its management, along with the associated improvement of institutional capacities to deliver services were reported, as highlighted below: 
Before, we only monitored our state, now we are looking at the Northeast as a whole and beyond. (...) We expanded not only the knowledge, but our vision of what happens, because nature has no barriers, no limits. Technician at a climate institution, Ceará state, participant of the DM, interview

\subsubsection{Limits and Possibilities of the WBI Approach Implementation in the Drought NLTA: Lessons to Be Remembered}

The implementation of the WBI pilot approach in the Drought NLTA program has raised some important points of discussion, in terms of methodological conclusions and contributions.

- Although relevant outcomes can happen in early implementation stages, programs framed as multi-stakeholder/multi-sector partnerships and strongly based on voluntary collaboration, such as the Drought NTLA, tend to take time to develop. The harvesting of significant outcomes will likely benefit from more implementation time. When the first harvesting was done (i.e., November 2014 January 2015), the program was in mid-term implementation phase. Results influenced by the program were starting to develop but were not yet ready to be reported as outcomes.

- The risk of having partners over-reporting positive outcomes to which the program has not truly contributed (e.g., to please the donor) can be overcome with rigorous methods. Triangulation of sources (combining document reviews, interviews, and other sources of information) and probing are extremely necessary. The framework provokes the analyst to do just that, by asking for evidence of the reported outcomes.

- Outcomes need to be interpreted taking the context into account (political environment, staff turnover, local and organizational culture, necessary support, etc.). Fostering partnerships needs respect for the various partners' capacities and their specific contexts. This principle allows the collaboration to generate outcomes that sometimes may be more realistic and more likely to be sustainable in the longer term than the planned, non-achieved outcomes. It is the case of the Piquet Carneiro DPP. While this plan did not define policy and management actions triggered as the drought progresses to higher stages, the plan was built through a broad consultation process, including discussions and the development of the plan proposal and intermediate validations with different stakeholders. As a result, it includes coherent and consistent management activities related to the preparation and risk reduction, and touches on response and disaster recovery for extreme drought effects in the municipality. It also provides a series of recommendations for institutional strengthening, adoption of management tools, 
training and capacity building, and infrastructure investments to provide effective risk management inherent to drought in the municipality of Piquet Carneiro. This rain-fed agriculture DPP has been approved at the State level as a model to follow by other Municipalities across the state and the region, and to feed into the State Plan.

- In such participatory approaches, it is key to involve all partners' representatives in the design of the Results Framework as much as possible - it will be more realistic and promote greater commitment. In the Drought NLTA implementation, because of the different paces of its pieces, not all of partners were already onboard when the RF was designed and reviewed. This resulted in the design of some milestones that only partially happened as the program developed.

- Perhaps the greatest limitation that this approach presents is the difficulty to link long-term, impact evaluation outcomes and, more specifically, indicators, to the program.

Requested by the WB Team, Drought NLTA partners suggested some indicators, but most of the suggested do not capture impact (e.g., \# of downloads of Drought Monitor information maps and narratives from the Drought Monitor website).

The difficulties with designing impact indicators for a drought resilience program like the Drought NLTA are that: (i) baselines are very challenging to establish and subsequently compare; (ii) attribution of impact of DM and the DPPs in increasing drought resilience might only be possible by comparing against when the next drought happens; and (iii) isolating the influence of an specific tool, such as the DM, from other influences in building such resilience, is very difficult. For example: the suggested indicator \# and distribution of monitoring network points across nine Northeast states, suggests that it would be possible to identify the impact of the DM in facilitating the expansion and penetration of climate and agriculture monitoring networks in Brazil. However, this impact is difficult to assess because other factors could be contributing equally or more to the expansion, such as economic and political decisions that have no direct relationship with the Drought Monitor.

Other suggested long-term indicators to be monitored that fall in a similar situation are:

- \# of cities that adopt urgent measures (such as water rationing) during drought declaration periods

- \# of water tank-trucks to provide water for human use during drought declaration periods

- \# of people with non-interrupted access to water during drought declaration periods

Designing and evaluating the impact of drought preparedness and other climate change adaptation and resilience initiatives remains a challenge that this specific approach, to date, could only begin to scratch, precisely because of the complexity of the factors that influence the outcomes. However, if contribution to impact can 
be accepted as a measure of success, then $\mathrm{OH}$ is an appropriate tool that can be combined with other techniques to evaluate impact.

\subsection{Conclusions}

In the early-mid stages of the program's implementation, interviews with some of the $80+$ professionals involved in the Drought NLTA, have revealed the key constraints and challenges to improving drought management in Brazil. The findings, reported in items 5 and 6 above, show that the initiative is contributing to address some of the reported challenges that Brazil persistently faces in proactively managing droughts.

The program is contributing significantly to both institutional and technical upgrades for better drought management, and two years after the beginning of its implementation, there is evidence of its influence. This evidence has been obtained by implementing a combined PM\&E approach, originally piloted by the WBI, which was designed to capture the complexity of institutional and behavioral changes evident in the Drought NLTA. While the methodology has some challenges and limitations, it has proven itself as an effective tool for understanding drought and climate change resilience and adaptation.

\section{References}

Earl, S., Carden, F., \& Smutylo, T. (2001). Outcome mapping: Building learning and reflection into development programs. Ottawa: IDRC.

Gold, J. (2013). Real-time learning in projects: Outcome management from design to completion. The World Bank Institute. Slides.

Gold, J. (2014). Guide for analyzing and learning from outcomes: Making sense of collected outcome information to improve development results. Washington, DC: The World Bank Institute.

Ministério da Integração Nacional (MI) e Instituto Interamericano de Cooperação para a Agricultura (IICA). (2013). Estudos Referentes ao Diagnóstico da Política nacional de Secas no Brasil: Relatório Contendo Diagnóstico e Embasamento para a Formulação de uma Política Nacional de Secas no Brasil. Consultor, Otamar de Carvalho.

Otoo, S., Agapitova, N., \& Behrens, J. (2009). The capacity development results framework: A strategic and results-oriented approach to learning for capacity development. Washignton, DC: The World Bank.

Wilhite, D. A. (2011, July 14-15). National drought policies: Addressing impacts and societal vulnerability. In Towards a compendium on national drought policy: Proceedings of an Expert Meeting, Washington, DC.

Wilson-Grau, R., \& Britt, H. (2012). Outcome harvesting. MENA Office, Ford Foundation. Available at http://www.outcomemapping.ca/resource/outcome-harvesting

World Bank. (2014a). Turn down the heat: Confronting the new climate normal. Washington, DC: World Bank. 
World Bank. (2014b). Outcome based learning field guide: Tools to harvest and monitor outcomes and systematically learn from outcomes. Available at https://wbi.worldbank.org/wbi/Data/wbi/ wbicms/files/drupal-acquia/wbi/Outcome-Based\%20Learning\%20Field\%20Guide.pdf

World Bank. (2014c). Cases in outcome harvesting. Available at http://www.outcomemapping.ca/ download/en_Cases\%20in\%20Outcome\%20Harvesting.pdf

World Bank. (2012). Turn down the heat: Why a $4{ }^{\circ} \mathrm{C}$ warmer world must be avoided. Washington, DC: World Bank Group.

World Bank Institute (WBI). (2013a). Guide for real-time outcome monitoring.

World Bank Institute (WBI). (2013b). Designing a multi - stakeholder results framework: A toolkit to guide participatory diagnostics and planning for stronger results and effectiveness.

World Bank Institute (WBI). (2014). Steps to frame capacity development results. Paper.

Open Access This chapter is licensed under the terms of the Creative Commons AttributionNonCommercial 3.0 IGO license (https://creativecommons.org/licenses/by-nc/3.0/igo/), which permits use, sharing, adaptation, distribution and reproduction in any medium or format, as long as you give appropriate credit to the World Bank, provide a link to the Creative Commons license and indicate if changes were made.

The opinions expressed in this chapter are those of the author(s) and do not necessarily reflect the views of the World Bank, its Board of Directors, or the countries they represent.

Any dispute related to the use of the works of the World Bank that cannot be settled amicably shall be submitted to arbitration pursuant to the UNCITRAL rules. The use of the World Bank's name for any purpose other than for attribution, and the use of the World Bank's logo, shall be subject to a separate written license agreement between the World Bank and the user and is not authorized as part of this CC-IGO license. Note that the link provided above includes additional terms and conditions of the license.

The images or other third party material in this chapter are included in the chapter's Creative Commons license, unless indicated otherwise in a credit line to the material. If material is not included in the chapter's Creative Commons license and your intended use is not permitted by statutory regulation or exceeds the permitted use, you will need to obtain permission directly from the copyright holder. 